\title{
An Action Research on the Effective English Phonetic Learning for College Students
}

\author{
Liang-Mei Kuo, ${ }^{1 *}$ \\ ${ }^{1}$ Lecturer, Department of Applied English, Tainan University of Technology \\ *Corresponding author. Email: t00119@mail.tut.edu.tw
}

\begin{abstract}
One of the key issues for effective English learning is to make students easily read and speak in English. Although most college students can pass the testing of English writing and/or reading in Taiwan, they still fail or afraid to speak in English. The Kenyon and Knott phonetic transcription, KK phonetic transcription, is wildly applied as the basic learning tool for most students in Taiwan. This research is aimed to improve the learning effectiveness by firstly developing a set of easy-understanding learning guide about phonetic and phonic rules, and followed by the motivational strategy of action learning that outreach the course learning to their families or friends to learn KK phonetic symbols. The process of this research was divided into 4 cycles of planning, implementing the efficient textbook learning and ask students to teach their families or friends, observations of the students' teaching materials and their teaching process by video, and students' share and reflection. The results show that motivational strategies of asking students to teach the KK Phonetic Transcription to someone that is close to them do have positive effects in improving the confidence of speaking English.
\end{abstract}

Keywords: Action research, English learning, Kenyon and Knott phonetic transcription.

\section{INTRODUCTION}

English is one of the most popular foreign language in Asia. Most students start to learn English from elementary school. One of the common scenarios in the college classroom of teaching English in Taiwan is that most student are scared to speak or talk in English. In spite of already passing the test of reading and writing, they are still lack of confidence when speaking in English. How to improve the motivation to speak and/or talk in English is the main challenge that most teachers teaching English as the major foreign language concerned.

When facing words with multi-syllables word decoding, irregular spelling pattern, special vowels and phonics, most students fail to read accurately. Systematic phonics instruction can be helpful for children to read better [1]. Cheng [2] also suggested that Phonics should be taught systematically and clearly. While meeting unknown words, students could sound out words through grapheme-phoneme conversation. The Kenyon and Knott (KK) Phonetic Transcription is the major unified transcription system in Taiwan, and wildly applied for all levels of students to learn English spelling and pronunciation [3]. KK phonetic symbols and phonics are the key factors to help students understand word recognition and pronounce confidently. If they could blend phonemes, improve spelling pattern, and find the path to word recognition on their own, students would have more interest and higher motivation to speak in English confidently.

Action research (AR) has a long history and been applied for English-as-a-Foreign Language (EFL) teachers to improve their teaching efficiency [4]. The peer feedback in college English writing class was studied to improve students' English writing skill [5]. The mobile learning of MOOCs (massive open online courses) was studied to evaluate the effectiveness of traditional teaching combined with MOOCs on college English writing course [6]. The way to filter useful information technologies to help teachers and guide students to improve English writing ability through mobile learning was proposed. The writing skill teaching with the aid of scaffolding theory by Vygotsky was also conducted [7]. If the teacher's active scaffolding processes can be applied at the early stage of the learning cycle students' confidence level can be increased and positive attitude towards writing can also be observed. Action research in cross-school and collaborative classroom-based EFL teaching study were developed in Korea and concluded that AR can be sustainable by making English teachers as researchers [8]. The 
implementation of action research projects among forty English language teachers of thirty Palestinian schools were proposed that aimed to study the outcomes of action research among teachers [9]. It was revealed that action research was a powerful, inquiry and exploratory tool that impacted teachers' classroom practices.

Learning strategies for EFL, specific actions such as seeking out conversation partners or giving possible encouragement, could enhance students' learning [10]. Planning for a language task was suggested as one of the effective EFL learning strategies. As mentioned previously that KK phonetic transcription plays an important role of EFL learning in Taiwan, the objective of this research is to plan the learning strategy for students to enhance their learning motivation by asking them to teach their family or friends to learn KK phonetic symbols. Follow the procedure of action research, an efficient KK phonetic transcription study guide is firstly developed in the plan stage. The students are taught with the study guide and asked to make a teaching plan for their families or friends. The students are also asked to report and share their actions of teaching their families or friends. Some observations and reflections from students and their families or friends are summarized. The results show that the learning strategy of outreach the course learning to the students' families or friends can significantly enhance the learning motivation and consequently improve the learning effectiveness.

\section{PLANNING FOR ACTION RESEARCH}

English is a compulsory course for college freshmen in Taiwan. As observed from the EFL courses in college over twenty years, pronunciation is the main challenge for most students. Students are afraid of speaking English even they had passed the reading and writing. The most effective way to enhance the confidence of speaking English is to re-teach the $\mathrm{KK}$ phonetic transcription for them. In order to make the learning of KK phonetics more meaningful, all the students were asked to teach their family or friends the KK phonetics. This project assignment can yield the meaningful and relevant learning motivation. It is also an opportunity to show their learning achievement and progress to those who are closed and cared persons. The four stages of plan, act, observe, and reflect of action research are scheduled for the course of English briefing, a course for the freshman in college, as shown in Figure 1. In addition to teach the briefing report skills, the KK phonetic transcription was firstly re-taught for more correct spelling and precise pronunciation.

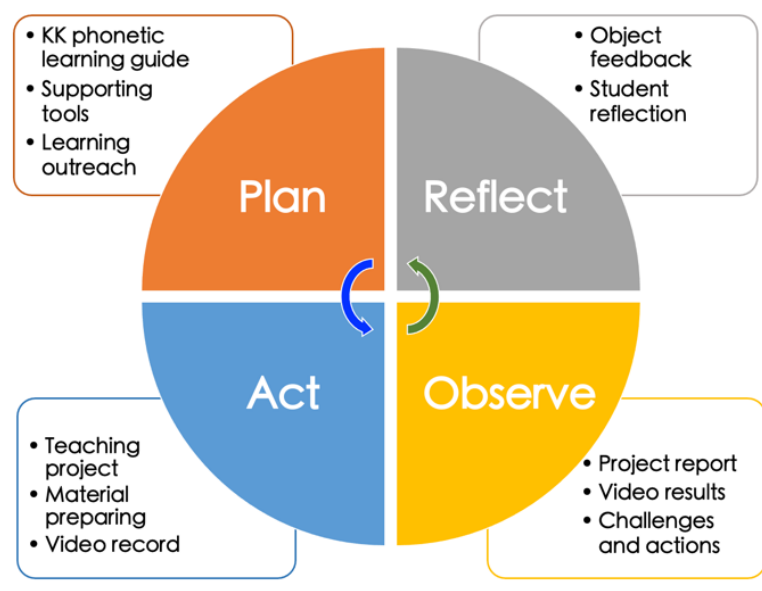

Figure 1 The for stages and the corresponding actions for this action research.

In the plan stage of this action research, an effective KK A learning guide is firstly developed for efficient learning. The learning guide is to build easy-toremembered rules for KK phonetic symbols as shown in Table 1. In addition to the phonetic rules, some illustration to help students to remember the connections. For instance, Figure 2(a) shows the emphasize the pronunciation with nose and Figure 2(b) spelling practice with figures. The learning guide is planned for 5 weeks of two hours course per-week. The first two weeks are focused on the basic vowels, consonants, and spelling. The special consonants and irregular vowels are taught in the third week. Special phonetic rules of unit 05 10 are scheduled for the $4^{\text {th }}$ and $5^{\text {th }}$ weeks.

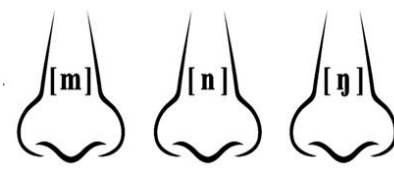

(a)

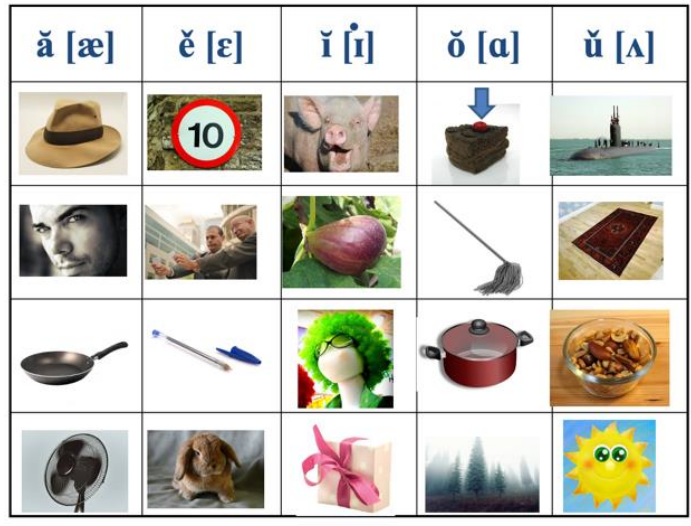

(b)

Figure 2 Examples of learning guide for KK phonetics, (a) pronounce with nose, and (b) spelling practice table. 
Table 1. Learning guide

\begin{tabular}{|c|c|c|}
\hline Unit & Phonetic rules & Phonetic symbols \\
\hline 01 & vowel & 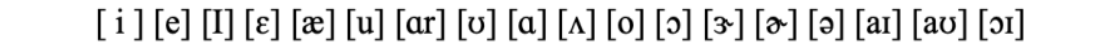 \\
\hline 02 & consonant & {$[\mathrm{p}][\mathrm{b}][\mathrm{t}][\mathrm{d}][\mathrm{k}][\mathrm{g}][\mathrm{f}][\mathrm{v}][\mathrm{s}][\mathrm{z}][\theta][\delta][\mathrm{h}]\left[\int\right][3][\mathrm{t}][\mathrm{dz}][\mathrm{m}][\mathrm{n}][\mathrm{g}][\mathrm{w}][\mathrm{j}][\mathrm{I}][\mathrm{r}]$} \\
\hline 03 & special consonant & $c[k] \quad j\left[d_{3}\right] \quad q u[k w] \quad y[j] \quad x[k s]$ \\
\hline 04 & irregular vowel & al [0] aw [0] $\operatorname{ar}[\mathrm{ar}]$ ay [e] ow [o] oo [v] oo [u] or [or] ir [3] ur [3] \\
\hline 05 & diphthong phonic & igh [ar] ou [av] ow [av] oi [эг] oy [эт] \\
\hline 06 & digraph consonant & $\operatorname{sh}[] \quad \operatorname{ch}[\mathrm{t}]] \quad$ wh $[\mathrm{hw}] \quad$ th $[\theta]$ th [ठ] \\
\hline 07 & compound consonant & $n g[n] \quad n k[n k] \quad p h[f] \quad g h[f]$ \\
\hline 08 & soft sound & ce $[s]$ ci $[s]$ cy $[s]$ ge $\left[d_{3}\right]$ gi $\left[d_{3}\right]$ gy $\left[d_{3}\right]$ \\
\hline 01 & r-controlled vowel & air $[\varepsilon r]$ are $[\varepsilon r]$ ear $[\varepsilon r]$ ear $[\mathrm{Ir}]$ eer [Ir] ere [Ir] \\
\hline 10 & 4-letter suffix phonic & tion [Jan] sion [Jən] sion [3ən] sure [3ə] \\
\hline
\end{tabular}

After the initial plan of training the students by the learning guide, students could understand and memorize the rules of phonics and successfully and effectively make correct spelling when facing the new words. This stage of learning also provide a good reference for students to make their own teaching practice as they are asked to outreach their learning results to be a teacher of KK phonetic symbols. They have to develop their own teaching materials to teach their family or friends. Applications of technologies can be applied to their project preparing, including the Microsoft PowingPoint software for making teaching materials, free video editor to make videos, were also toughed in the classroom.

\section{ACTION RESEARCH FOR LEARNING THROUGH TEACHING}

The action stage of action research is to complete the memory, cognitive, comprehension, metacognitive, affective, and social learning strategies of learning. To make an teaching material and to teach are great challenges both in teaching expertise and psychological pressure for freshman students. It is a good opportunity for them to transform and help to recall what they had learned. The objective is to enhance their learning attitude and motivation to be more actively. They also have to make a video to record their teaching procedure and results. Feedback from their teaching object should also been recorded in the video. The results should include introduction of the teaching object, teaching procedure, challenges and how to overcome, feedback from the teaching object, and their reflections from this project.

Most students asked their families to help them by playing as the teaching object of the project. Family members of parents and brothers or sisters are commonly observed. The age of the teaching objects can be ranged from 4 to over 50 years old. One observation of the students' action project shown in Figure 3 is introduced.
The teaching object is the student's mother. The teach plan was to illustrate and guide her mother to make correct spell with basic vowels and consonants. The procedure recorded in the video showed that although the mother pronounced with native accent she can spell the KK phonetics correctively. The resulting feedback from the mother indicated that she felt very fun and happy to have the chance to study with her daughter together. Some reflections were reported from the student as:

- There do exist many challenges in teaching with unexpected response from the teaching object.

- The whole action process of material preparing, teaching, take photo and video, and report summary was exhausting, yet felt very fruitful.

- She not only learned the way to spell, but also learned the good experience for an action plan, execution, and report summary for the rest courses.

Through the cycle of action and reflection, most students finished their plans. One of the most common experience gained as the students reflected is that teaching is much more difficult than they ever imagined. Most students reflected that they could understand the difficult situation of teachers.

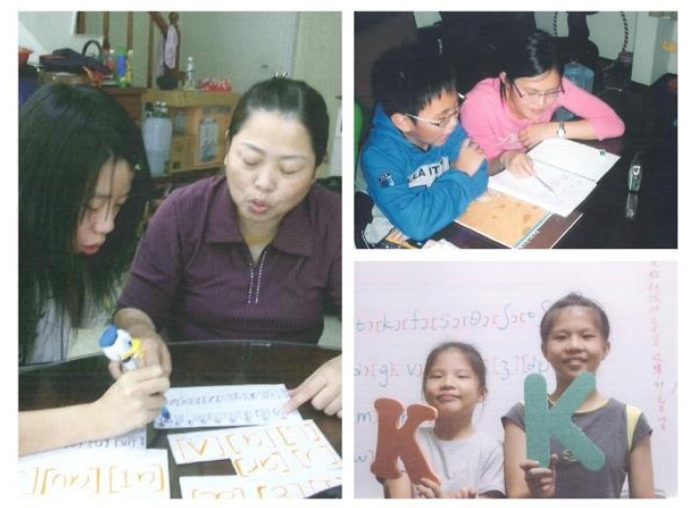


Figure 3 The action of carrying out the teaching project.

\section{CONCLUSION}

Action research for $\mathrm{KK}$ phonetic transcription learning was studied with an EFL course of college freshman. For most students to learn EFL, correct spelling and precise pronunciation were the main challenge for them to speak in English with confidence, even though they had passed the writing and reading tests in the entrance examination of college. This research is aimed to improve the learning effectiveness by firstly developing a set of easy-understanding learning guide about phonetic and phonic rules, and followed by the motivational strategy of action learning that outreach the course learning to their families or friends to learn KK phonetic symbols. The four stages of action research, plan, act, observe and reflect are scheduled with the course. The final project was that they have to develop their own teaching materials to teach their family or friends to learn KK phonetic symbols. Project results must be presented in a video that tells the story of their teaching action, including the introduction of their teaching object, teaching procedure, challenges and how to overcome, feedback from the teaching object, and their reflections from this project action. Some conclusions are summarized as followed.

- Through this action project, the learning motivation was significantly enhanced for most students. They realized that their learning was very important because they have to teach their families based on their learning results.

- The learning guide not only played as a tool for the students to learn KK phonetics, but also applied as the teaching materials for them in the teaching project. The learning guide together with the other video editing and multi-media software formed a set of valuable supporting tools for this action research.

- With the supporting tools and the enhanced learning motivation, most students learned the KK phonetic transcription and finished their project, i.e., they proved themselves the successful learning of $\mathrm{KK}$ phonetics by teaching their families or friends to learn.

- A common experience gained as the students reflected is that teaching is much more difficult than they ever imagined. Most students reflected that they could understand the difficult situation of teachers through this action project.

- Action research in this paper reveals that "action"the students were asked to finish can both enhance the learning motivation and learning effectiveness. The benefit of applying action research in EFL related teaching classroom is proved and can be further encouraged.

\section{REFERENCES}

[1] L.C. Ehri, S.R. Nunes, S.A. Stahl and D.M. Willows, Systematic phonics instruction helps students learn to read: evidence from the national reading panel's meta-analysis, Review of Educational Research, vol. 71, no. 3, 2001, pp. 393447.

DOI:

http://dx.doi.org/10.3102/00346543071003393

[2] Y.L. Cheng, Effects of the revelational phonics approach on Chinese L1 EFL beginners' knowledge of the English alphabetic principle: Further evidence from 'whole word', 'single-letter-sound', and 'digraph' reading. Chang Gung Journal of Humanities and Social Sciences, vol. 8, no. 2, 2015, pp. 347-379.

[3] A. Vijunas, Some remarks regarding English transcription practices in Taiwan. Taiwan Journal of Linguistics, vol. 102, no. 1, 2014, pp. 25-61. DOI: http://dx.doi.org/10.6519/TJL. 2014.12(1).2

[4] G. Crookes, Action research for second language teachers: going beyond teacher research, Applied Linguistics, vol. 14, no. 2, 1993, pp. 130-144.

[5] W. Wang, Peer Feedback in Chinese college English writing class: using action research to promote students' English writing, Journal of Language Teaching and Research, vol. 7, no. 5, 2016, pp. 958966. DOI: http://dx.doi.org/10.17507/ jltr.0705.17

[6] X. Guo, Action research on college English writing based on information technology from the perspective of Moocs, English Language Teaching, vol. 9, no. 11, 2016, pp. 48-52. DOI: https://doi.org/ 10.5539/elt.v9n $11 \mathrm{p} 48$

[7] H. Ahn, Teaching writing skills based on a genre approach to L2 primary school students: an action research, English Language Teaching, vol.5, no. 2, 2012, pp. 2-16. DOI: https://doi.org/10.5539/ elt.v5n2p2

[8] Y.O. Jong and C.K. Jung, The Methodological approach of action research in the field of English language teaching, English Language \& Literature Teaching, vol. 21, no. 2, 2015, pp. 23-40.

[9] M. Dajani, Preparing palestinian reflective English language teachers through classroom based action research, Australian Journal of Teacher Education, vol. 40, no. 3, 2015, pp. 115-139. DOI: http://dx.doi.org/10.14221/ajte.2014v40n3.8

[10] R.L. Oxford, Language learning styles and strategies: Concepts and relationships, International Review of Applied Linguistics in Language Teaching, vol.41, 2003, pp. 271-278. DOI: http://dx.doi.org/10.1515/ IRAL.2003.012 